\title{
ВЛИЯНИЕ СКОРОСТИ ГИДРАТАЦИИ ИЗВЕСТИ И АНГИДРИТА НА ОБЪЕМНЫЕ ИЗМЕНЕНИЯ И ПЛАСТИЧЕСКУЮ ПРОЧНОСТЬ СЛАНЦЕЗОЛЬНОГО КАМНЯ
}

\author{
Е. А. ГАЛИБИНА,
}

кандидат технических наук н. Л. ДИЛАКТОРСКИИ,

доктор геолого-минералогических наук

Пылевидная зола, образующаяся при сжигании прибалтийских горючих сланцев, наряду с гидравлически активными соединениями содержит значительное количество зерен извести, ангидрита и стекловатых частиц ['].

Замедленная гидратация части зерен извести и ангидрита сопровождается появлением в твердеющем вяжущем напряжений, ведущих к снижению механических свойств изделий, особенно резко сказывающихся при изготовлении последних в автоклаве. По мнению ряда исследователей (см., например, $\left.\left[{ }^{2}\right]\right)$, наилучшим приемом, предупреждающим возникновение объемных изменений при обработке изделий из ячеистых бетонов в автоклаве, следует признать предварительное их пропаривание при $80^{\circ}$ в течение шести часов. Однако и этот прием, как показывает практика, не всегда обеспечивает получение доброкачественного матернала, так как в ряде случаев, несмотря на предварительное пропаривание, появляющиеся в условиях автоклавного твердения объемные изменения ухудшают технические свойства изделий.

Исходя из сказанного, цель нашей работы и заключалась в проверке эффективности влияния химических добавок (наряду с предварительной пропаркой) на скорость гидратации присутствующих в золе извести, ангидрита, объемные изменения и пластическую прочность твердеющих в различных условиях сланцевых зол.

\section{Методика исследований}

Исследованию подвергались три пробы пылевидных слачцевых зол, размолотых в шаровой мельнице до удельной поверхности $2500 \mathrm{~cm}^{2} / \mathbf{r}$ (по Товарову), химическнй состав которых приведен в табл. 1 .

Химический состав исследованных сланцевых зол *

Таблица 1

\begin{tabular}{|c|c|c|c|c|c|c|c|c|c|c|c|c|}
\hline \multirow[b]{2}{*}{$\begin{array}{c}\text { Пылевидная } \\
\text { сланцевая зола }\end{array}$} & \multicolumn{4}{|c|}{ Соде ржан и е } & \multicolumn{2}{|c|}{ о ки слов, } & \multicolumn{6}{|c|}{$\%$ на сухое вешество } \\
\hline & $\mathrm{SiO}_{2}$ & $\mathrm{Al}_{2} \mathrm{O}_{3}$ & $\mathrm{Fe}_{2} \mathrm{O}_{3}$ & $\mathrm{CaO}$ & $\mathrm{MgO}$ & $\begin{array}{r}\mathrm{K}_{2} \mathrm{O}+ \\
+\mathrm{Na}_{2} \mathrm{O}\end{array}$ & $\mathrm{CO}_{2}$ & $\mathrm{SO}_{3}$ & $\begin{array}{c}\text { Хими- } \\
\text { чески } \\
\text { связан- } \\
\text { ная } \\
\mathrm{H}_{2} \mathrm{O} \\
\end{array}$ & Сумма & $\begin{array}{c}\mathrm{CaO} \\
\text { саобод- } \\
\text { ноее }\end{array}$ & $\begin{array}{r}\mathrm{SiO}_{2} \\
\text { раство- } \\
\text { римое }\end{array}$ \\
\hline $\mathrm{K}_{\mathrm{cm}}$ & 31,37 & 8,60 & 5,65 & 41,44 & 3,47 & 2,54 & 1,98 & 4,84 & 0,88 & 100,77 & 19,35 & 17,16 \\
\hline $\mathrm{K}_{\mathrm{50}}$ & 29,60 & 7,43 & 6,26 & 42,84 & 4,04 & $\begin{array}{c}\text { Не } \\
\text { опреде- } \\
\text { лялись }\end{array}$ & 2,64 & 5,50 & 0,15 & 98,46 & 18,28 & 17,00 \\
\hline $\mathrm{A}_{2}$ & 29,06 & 7,30 & 5,42 & 46,85 & 2,76 & 2,52 & 1,75 & 2,55 & 1,40 & 100,04 & 23,05 & $\begin{array}{c}\mathrm{He} \\
\text { опреде- } \\
\text { лялось }\end{array}$ \\
\hline
\end{tabular}

* Анализы выполнены химикамн-аналитиками ИССМ АН ӘССР Л. Тамм н Х. Раудоя. 
Определение пластической прочности в твердеющем вяжущем пронзводилось коннческим пластометром на образцах сланцезольного теста нормальной консистенции по методу, описанному в работе []. Степень гидратации извести и ангидрита устанавливалась с помощью прямого определения связанной воды [4]. Объемные изменения сланцезольного вяжущего, твердеющего при повышенной температуре $\left(80^{\circ} \mathrm{C}\right)$, измерялись ртутным волюмометром. Сроки схватывания вяжущего определялись при помощи иглы Внка. При подготовке проб растворимые добавки $\left(\mathrm{CaCl}_{2}, \mathrm{MgCl}_{2}, \mathrm{NH}_{4} \mathrm{Cl}\right.$. $\mathrm{NaCl}, \mathrm{KCl}$ и др.) вводились вместе с водой затворения, нерастворимые в тонкомолотом внде предварительно смешивались с золой (двуводный, полуводный гипс и др.)

\section{Твердение сланцезольного камня в нормальных условиях}

С точки зрения характера воздействия на сроки схватывания сланцевой золы изученные нами добавки могут быть разделены на две группы. К первой группе относятся те добавки, введение которых способствует сокращению сроков схватывания $\left(\mathrm{CaCl}_{2}, \mathrm{MgCl}_{2}, \mathrm{NH}_{4} \mathrm{Cl}, \mathrm{NaNO}_{3}\right.$, гипс, $\mathrm{Al}_{2}\left(\mathrm{SO}_{4}\right)_{3}$ и др.); ко второй - те, которые удлиняют сроки схватывания сланщевой золы по сравнению с вяжущим, твердеющим без добавок ( $\mathrm{KCl}, \mathrm{NaCl}$, растворы глюкозы, растворимое стекло и др.).

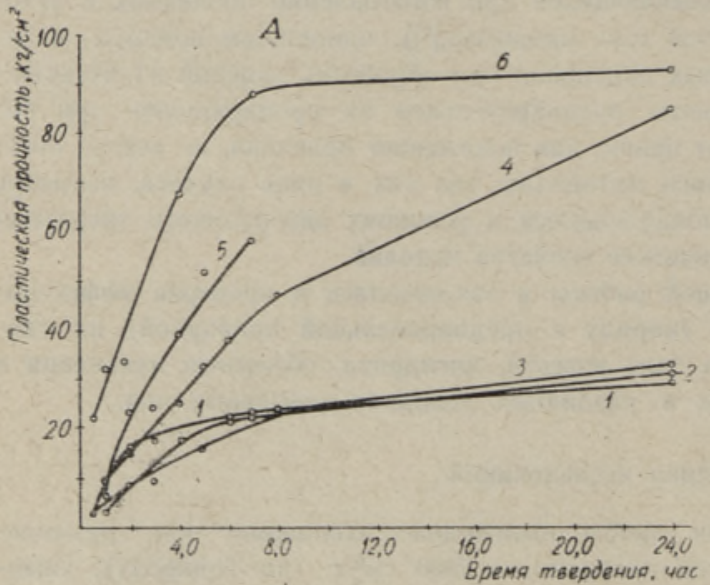

Фиг. 1.

Влияние химических добавок. ускоряющих и замедляющих схватывание, на пластическую прочность сланцезольного вяжущего, твердеющего в нормальных условиях.

A. Негашеная молотая пылевндная сланцевая зола с добавками: 1 - сланцезольное тесто (без добавок)

$2-1,0 \% \quad \mathrm{NH}_{4} \mathrm{Ci}$

$3-1,0 \% \quad \mathrm{CaCl}_{2}$

$4-3,0 \% \quad \mathrm{NH}_{4} \mathrm{Cl}$

$5-5,0 \% \quad \mathrm{NH}_{4} \mathrm{Cl}$

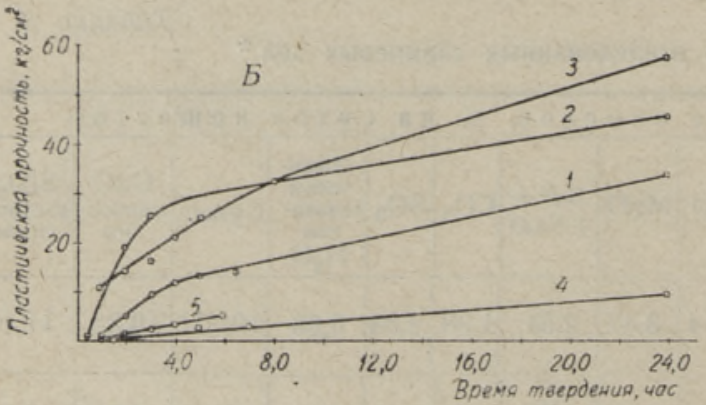

$6-5,0 \% \mathrm{CaCl}_{2}$

Б. Негашеная молотая пылевидная сланцевая зола с добавками: 1 - сланцезольное тесто (без добавок)

$2-0,2 \% \quad \mathrm{Al}_{2}\left(\mathrm{SO}_{4}\right)_{3}$

$3-0,5 \% \quad \mathrm{Ar}_{2}\left(\mathrm{SO}_{4}\right)_{3}$

$4-1,0 \%$ глюкозы

$5-0,5 \%$ растворимого стекла

На фиг. 1 представлены данные, характеризующие пластическую прочность твердеющего в нормальных условиях вяжущего в зависимости от количества и вида введенных в золу добавок. Эти данные показывают, что между сроками схватывания и пластической прочностью вяжущего наблюдается определенная зависимость: добавки, сокращаю. 
шие сроки схватывания, приводят к ускорению, а удлиняющие - $к$ замедлению скорости нарастания прочности во время первоначального затвердевания. Из этих данных видно также, что степень ускорения нли замедления нарастания прочности в первоначальные сроки твердения зависит от количества введенной в золу добавки (фиг. $1 A, E)$.

Кривые, характеризующие кинетику гидратации присутствующих в золе нзвести, ангидрита и других минералов, показывают, что в вяжущем, твердеюшем в нормальных условиях $\left(20^{\circ}\right)$ и без добавок, этот процесс идет крайне медленно (фиг. 2). Так, к 72 часам гидратируется только около $88 \%$ свободной извести (фиг. 2, кривая 1 ). При этом скорость гидратации неодинакова во времени: в первые 8 часов гасится 70 , а в последующие 64 часа - только $18 \%$ извести, присутствующей в золе. Не заканчивается к этому сроку (72 часа) и гидратация присутствующих в золе ангидрита, двухкальциевого силиката и других соединений, о чем свидетельствует кривая, характеризующая количество воды, связанной с этими минералами (фиг. 2, кривая 5).

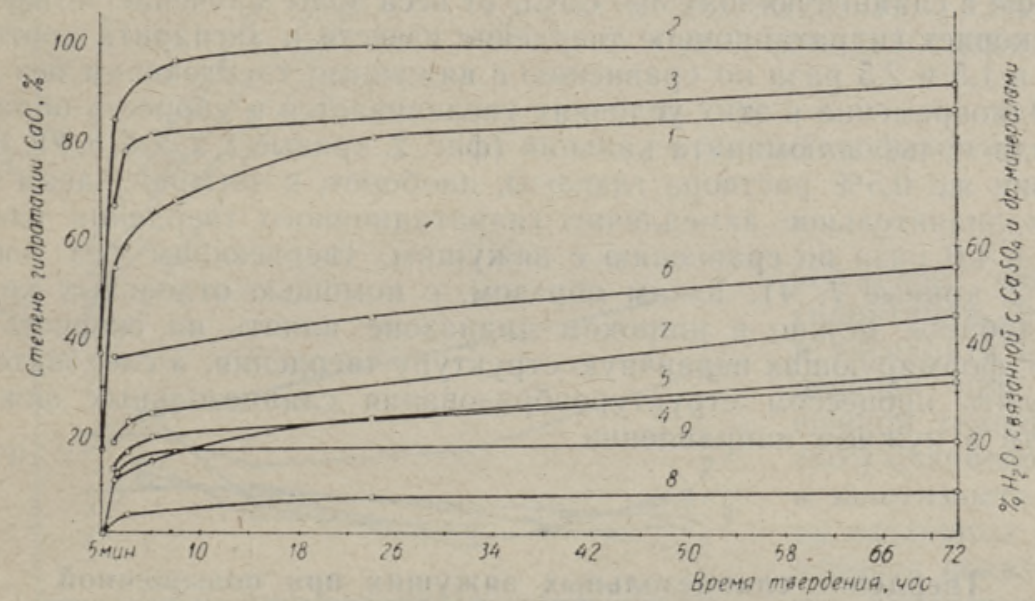

Фиг. 2. Влияние отдельных химических добавок на скорость гидратации $\mathrm{CaO}$ и $\mathrm{CaSO}_{4}$, присутствующих в золе.

Негашеная молотая пылевидная сланцевая зола с добавками: $I$ - сланцезольное тесто (без добазок); $2-3,0 \% \mathrm{CaCl}_{2} ; 3-$ $0,1 \% \quad \mathrm{Al}_{2}\left(\mathrm{SO}_{4}\right)_{3} ; 4-0,5 \%$ глюкозы; 5 - сланцезольное тесто (без добавок); $6-3,0 \% \quad \mathrm{CaCl}_{2} ; 7-0,1 \% \mathrm{Al}_{2}\left(\mathrm{SO}_{4}\right)_{3} ; 8=$ сланцезольное тесто (без добавок); $9-3,0 \% \mathrm{CaCl}_{2}$.

Кривые $1-4$ характеризуют степень гидратации $\mathrm{CaO}$; кривые $5-7$ - количество воды, связанной с $\mathrm{CaSO}_{4}$ и другими минералами, и кривые $8-9$ - количество $\mathrm{CaO}$, связанной в новообразования.

Скорость сзязывания $\mathrm{CaO}$ в новообразования типа гидросульфоалюминатов кальция также непостоянна: в первые 4-6 часов она значительно больше, чем в последующем (фиг. 2, кривая 8 ).

Образование гидросиликатов кальция как в начальные, так и в последуюшие сроки протекает в нормальных условнях очень медленно.

Bсе сказанное о кинетике гидратации минералов, присутствуюших в золе, и о скорости связывания извести в новообразования позволяет говорить о том, что образование первичного сростка определяется в: основном гидратационным твердением присутствующих в золе извести и ангидрита и образованием гидросульфоалюмината кальция.

Вторичная, гидросиликатная структура появляется в твердеюшем в нормальных условиях вяжущем в более поздние сроки. 
Изучение сроков схватывания сланцевых зол и скорости гидратации извести, ангидрита и других минералов в зависимости от вида введенных в золу добавок показало, что добавки, сокращающие сроки схватывания ( $\mathrm{CaCl}_{2}, \mathrm{NH}_{4} \mathrm{Cl}, \mathrm{Al}_{2}\left(\mathrm{SO}_{4}\right)_{3}, \mathrm{CaSO}_{4} \cdot 2 \mathrm{H}_{2} \mathrm{O}$ и др.), ускоряя гидратационное твердение присутствующих в золе извести и ангидрита iі образование гидросульфоалюмината кальция, способствуют повышению прочности первичного сростка по сравнению с вяжущим, твердеющим без добавок. Добавки, удлиняющие сроки схватывания сланцевых зол (раствор глюкозы, растворимое стекло, $\mathrm{KCl}, \mathrm{NaCl}$ и др.), замедляют гидратационное твердение $\mathrm{CaO}, \mathrm{CaSO}_{4}$ : в их присутствии прочность первичного сростка оказывается меньшей, чем прочность вяжущего, твердеющего без добавок.

Существенным является тот факт, что в присутствии солей, как сокращающих, так и удлиняющих сроки схватывания, скорость процессов, обусловливающих формирование скелетного сростка, соответственно увеличивается или уменьшается уже в первые часы твердения. Так, введение в сланцевую золу $3 \% \mathrm{CaCl}_{2}$ от веса золы в течение четырех часов ускоряет гидратационнае тверденне извести-н ангидрита соответственнө в 1,5 и 2,5 раза по сравненню с вяжущим, твердеющим без добавок. Одновременно в этих условнях увеличивается и скорость образования гидросульфоалюмнната кальция (фиг. 2 , кривые $1,2,5,6,8,9$ ). В присутствии же $0,5 \%$ раствора глюкозы, наоборот, к четырем часам отмечается значительное замедленне гидратационного твердения извести: почти в 4,0 раза по сравнению с вяжущим, твердеющим без добавок (фиг. 2 , кривые 1,4 ). Таким образом, с помощью отдельных химиче ских добавок можно в широком диапазоне влиять на скорость пролессов, формирующих первичную структуру твердения, а следовательно, управлять процессом структурообразования сланщезольных вяжущих веществ в нужном направлении.

\section{Твердение сланцезольных вяжущих при повышенной температуре $\left(80^{\circ}\right)$}

На фиг, 3 представлены данные, характеризующие изменение величины пластической прочности во времени при температуре $80^{\circ}$ в зависимости от вида и количества введенных в золу добавок. Из рисунка видно, что в сланцевой золе, твердеющей при $80^{\circ}$ без добавок, вслед за резким увеличением пластической прочности, наблюдающимся в течение первых 60 минут, следует ее спад, продолжающийся, как правило, в течение последующих $1-4$ часов твердения и сменяющийся в дальнейшем медленным нарастанием прочности (фиг. 3 , кривая 1 ).

Химические добавки, сокрашающие сроки схватывания, по своему влиянию на процесс структурообразования в твердеющем при $80^{\circ}$ сланпезольном вяжущем могут быть разделены на две группы.

Одни из них $\left(\mathrm{CaCl}_{2}, \mathrm{NH}_{4} \mathrm{Cl}, \mathrm{MgCl}_{2}\right)$, введенные в количестве трехпяти процентов от веса золы, значительно повышают прочность вяжушего. Например, в присутствии $3,0 \% \mathrm{CaCl}_{2}$ к четырем часам твердения прочность вяжущего в 14 раз больше, чем вяжущего, твердеющего без добавок (фиг. 3 , кривые 1,4 ). В присутствии других добавок (двуводного и полуводного гипса, $\left.\mathrm{NaNO}_{3}, \mathrm{Al}_{2}\left(\mathrm{SO}_{4}\right)_{3}\right)$ начальная прочность первичного сростка не превышает прочности вяжушего, твердеющего без добавок в течение первого часа, а в дальнейшем между $1-4$ часами отмечается ее спад (фиг. 3 , кривые 1,12 ). Введение в сланцевую золу добавок, удлиняющих сроки схватывания в нормальных условиях $-\mathrm{KCl}$, 
$\mathrm{NaCl}, \mathrm{K}_{2} \mathrm{SO}_{4}, \mathrm{Na}_{2} \mathrm{SO}_{4}$, жидкого стекла и растворов глюкозы (как в малых, так и в больших концентрациях), - не ликвидируют в твердеющем при $80^{\circ}$ вяжущем временного снижения прочности (фиг. 3 , кривые $1-3$ ).

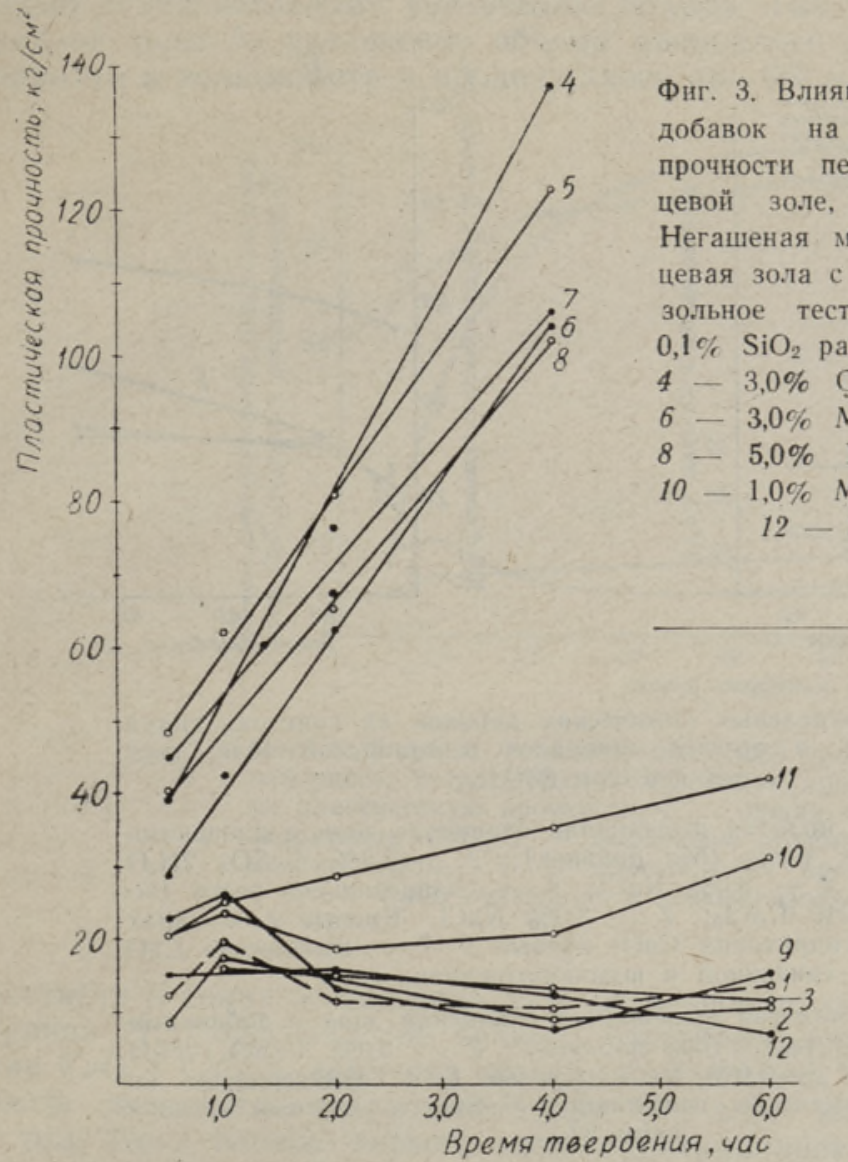

Изучение скорости гидратации извести и ангидрита в твердеющей при повышенной температуре $\left(80^{\circ}\right)$ сланцевой золе в зависимости от вида введенных в золу добавок показывает, что хлористые соли кальция способствуют ускоренной гид-

ратации активных соединений уже в первые минуты твердения. Скорость гидратации $\mathrm{CaO}, \mathrm{CaSO}_{4}$ в присутствии $3,0 \% \mathrm{CaCl}_{2}$ К 60 минутам твердения возрасстает соответственно в 1,3 и 1,5 раза, а скорость связывания $\mathrm{CaO}$ в новообразования - в 1,5 раза по сравнению с вяжущим, твердеющим без добавок (фиг. $4 A$, кривые $1,3,6$ и фиг. $4 E$, кривые $1,3)$.

В присутствии $5 \%$ двуводного гипса, так же как и хлористого кальция, сокрашающего сроки схватывания сланцевой золы, отмечается меньшая скорость гидратации извести и ангидрита по сравнению с вяжущим, твердеющим с $\mathrm{CaCl}_{2}$. Так, степень гашения $\mathrm{CaO}(90 \%)$, наблюдаемая к 60 минутам при добавке $3 \% \mathrm{CaCl}_{2}$, в присутствии гипса достигается только к двум часам. В последнем случае уменьшается и скорость гидратации ангидрита, клинкерных минералов, а также скорость связывания $\mathrm{CaO}$ и $\mathrm{CaSO}_{4}$ в новообразования по сравнению с вяжущим, твердеюшим с добавкой $\mathrm{CaCl}_{2}$ (фиг. $4 A$, кривые 1,2 и фиг. 45 , кривые 1,2 ).

Проведенные исследования показали, что все добавки, удлиняюцие сроки схватывания сланцевой золы, замедляют гидратацию присутствуюших в золе извести, ангидрита и других минералов (фиг. $4 A$, кривые $1,4,5,7$ и фиг. 4 Б, кривые $1-4$ ). Таким образом. скорость гид- 
ратации извести и ангидрита, а также скорость связывания СаО в новообразования зависит от вида введенных в золу добавок.
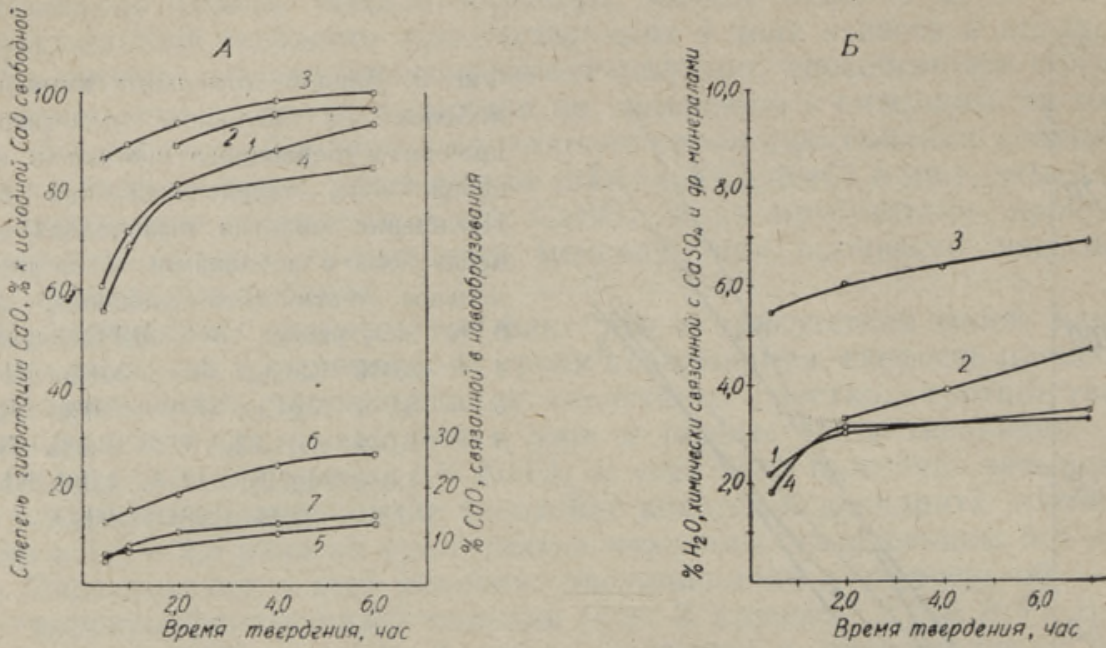

Фиг. 4. Влияние отдельных химических добавок на кинетику гидратации $\mathrm{CaO}, \mathrm{CaSO}_{4}$ и других минералов в сланцевой золе, твер. деющей при $80^{\circ} \mathrm{C}$.

A. Негашеная молотая пылевидная сланцевая зола с добавками: 1 - сланцезольное тесто (без добавок); $2-5,0 \% \quad \mathrm{CaSO}_{4} \cdot 2 \mathrm{H}_{2} \mathrm{O}$; $3-3,0 \% \quad \mathrm{CaCl}_{2} ; 4-3,0 \% \mathrm{NaCl} ; 5$ - сланцезольное тесто (без добавок); $6-3,0 \% \mathrm{CaCl}_{2} ; 7-3,0 \% \mathrm{NaCl}$. Кривые $1-4$ харак. тернзуют степень гидратации $\mathrm{CaO}$; кривые 5-7- количестізо СaO, связанной в новообразования.

Б. Негашеная молотая пылевидная сланщевая зола с добавками: 1 - сланцезольное тесто (без добавок); $2-5,0 \% \quad \mathrm{CaSO}_{4} \cdot 2 \mathrm{H}_{2} \mathrm{O}$; $3-3,0 \% \mathrm{CaCl}_{2} ; 4-3,0 \% \mathrm{NaCl}$. Кривые $1-4$ характеризуют количество воды, химически связанной с $\mathrm{CaSO}_{4}$ и другими минералами, \%.

Сравнение кривых, характеризующих структурообразованне и кинетику гидратации $\mathrm{CaO}$ и $\mathrm{CaSO}_{4}$ в твердеющем при $80^{\circ}$ вяжущем, показывает, что независимо от количества и вида введенных в золу добавок, заме́длящих или ускоряющих сроки схватывания, спад прочности происходит в момент образования первичного сростка при еще незакончившемся процессе гидратации извести и ангидрита (фиг. 5 , кривые 1 -3). Дальнейшее нарастание прочности определяется скоростью образования вторичной структуры, которая в условиях повышенных температур возникает в более ранние сроки твердения.

Снижение прочности в твердеющем при $80^{\circ}$ вяжущем зависит от скорости процессов, формирующих первичную структуру твердения. Скорость гидратационного твердения $\mathrm{CaO}$ и $\mathrm{CaSO}_{4}$, а также скорость связывания их гидратов в новообразования должна быть такой, чтобы возникающий в течение первого часа твердения первичный сросток обладал достаточной прочностью и не разрушался при дальнейшей гидратации извести и ангидрита. Это условие соблюдается при добавке к золе, например, $\mathrm{CaCl}_{2}, \mathrm{MgCl}_{2}, \mathrm{NH}_{4} \mathrm{Cl}$ и др. (фиг. 3, кривые 1, 4, $7,8)$. 
Кривые, характеризующие величину объемных изменений в твердеющем при $80^{\circ}$ вяжущем, показывают, что напряжения, появляющиеся в твердеющей смеси в момент образования первичного сростка, приводят к значительному увеличению объема. Так, при твердении пылевидной золы $\mathrm{A}_{2}$ увеличение объема начиналось сразу по погруженин образца в волюмометр и продолжалось при $80^{\circ}$ в течение шести часов.

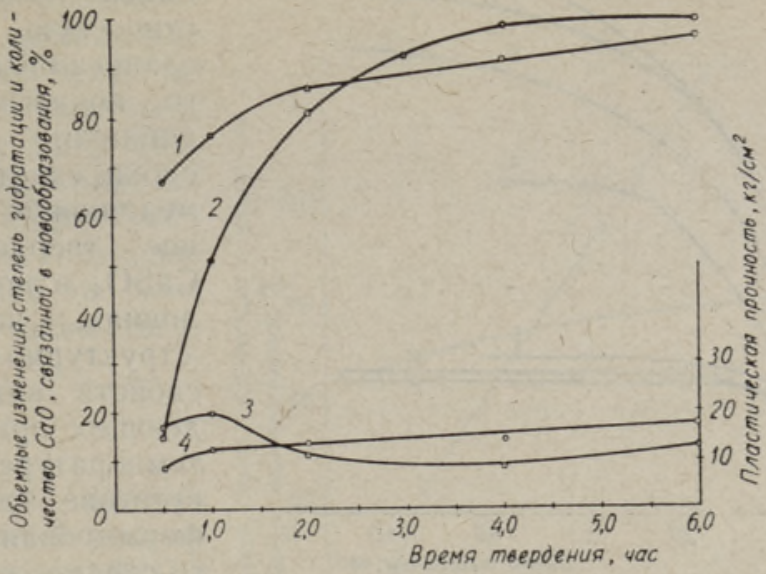

Фиг, 5. Влияние величины объемных изменений вяжущего, твердеющего без добавок при $80^{\circ} \mathrm{C}$, на пластическую прочность: $I$ - общая степень гидратации $\mathrm{CaO} ; 2$ - увеличение пбъема, \% к максимальному; 3 - пластическая прочность, $4-\mathrm{CaO}$, связанная в новообразования.

достигая к конщу этого срока $54 \%$ от первоначального объема (фиг. 6. кривая 1). Сопоставление кривых, характеризующих степень гидратации $\mathrm{CaO}$ и $\mathrm{CaSO}_{4}$, величину объемных изменений и пластическую прочность вяжущего, твердеющего при $80^{\circ}$, дает возможность говорить O том, что в течение первого часа гидратационное твердение извести и ангидрита, несмотря на то, что оно сопровождается увеличением объема, не ведет к понижению прочности - она непрерывно растет. К концу этого периода величина пластической прочности достигает $20 \mathrm{kr} / \mathrm{cm}^{2}$, причем за это время гидратируется около $80 \%$ свободной известн. Дальнейшая гидратация $\mathrm{CaO}$ и $\mathrm{CaSO}_{4}$ сопровождается не только значительным увеличением объема, но и снижением пластической прочности іфиг. 5 , кривые $1,3,4$ и фиг. 6 , кривая 1 ). Следовательно, причина спада прочности в вяжущем, твердеющем при $80^{\circ}$, который происходит до окончания гидратации извести и ангидрита, заключается в появлении напряжений, возникающих в структуре в период формирования первичного скелетного сростка, Отсюда следует, что гидрата ционный эффект присутствующих в золе $\mathrm{CaO}$ и $\mathrm{CaSO}_{4}$ в вяжущем, твердеющем при повышенной температуре $\left(80^{\circ}\right)$, используется неполностью, так как напряжения, развивающиеся в момент формирования скелетного сростка, разрушают его.

Естественно, что выяснение условий, способствующих уменьшению напряжений, необходимо для улучшения производства автоклавных изделий, подвергаемых предварительному пропариванию. Данные, характеризующие влияние химических добавок на величину напряжений, появляюшихся в вяжущем, твердеющем при $80^{\circ}$, показывают, что с по- 
мощью некоторых из них можно широко изменять не только величину, но и продолжительность периода объемных изменений (фиг. 6, кривые $1-7)$.

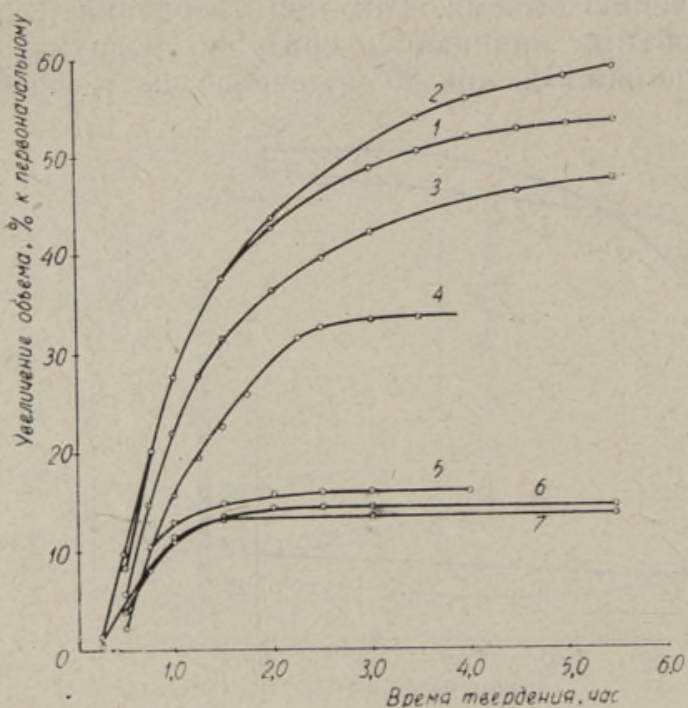

Фиг. 6. Влияние отдельных химнческих добавок на объемные изменения твердеющей при $80^{\circ} \mathrm{C}$ сланцевой золы в момент образования первичного сростка. Негашеная молотая пылевидная сланцевая зола с добавками: 1 - сланцезольное тесто (без добавок); $2-0,5 \%$ жндкого стекла; $3-0,5 \%$ $\mathrm{Al}_{2}\left(\mathrm{SO}_{4}\right)_{3} ; 4-1 \% \mathrm{NH}_{4} \mathrm{Cl} ; 5-3,0 \% \quad \mathrm{CaCl}_{2} ;$ $6-5,0 \% \mathrm{CaCl}_{2} ; 7-5,0 \% \mathrm{NH}_{4} \mathrm{Cl}$. чем те, которые отмечаются в вяжущем, твердеющем без добавок (фиг. 6, кривые 1,2 ).

Добавки, сокращающие сроки схватывания и ускоряющие гидратационное твердение извести и ангидрита, по величине развиваемых в тверлеющем при $80^{\circ}$ вяжущем напряжений могут быть разделены на две группы.

Одни из них, незначительно уменьшающие абсолютную величину объемных изменений и не изменяющие их продолжительности, не улучшают структурно-механических свойств (двуводный, полуводный гипс, сернокислый алюминий и др.). Так, введение в сланцевую золу $0,5 \%$ $\mathrm{Al}_{2}\left(\mathrm{SO}_{4}\right)_{3}$ способствует лишь незначительному уменьшению объема по сравнению с твердеющим без добавок вяжущим - 47,5 против 54\% от первоначального объема (фиг. 6, кривая 3 ). Такое незначительное уменьшение объема недостаточно, чтобы ликвидировать напряжения, приводящие к снижению прочности. В результате этого в присутствии сернокислого алюминия в период формирования скелетного сростка отмечается спад прочности.

Введение в золу других добавок, также сокращающих сроки схватывания сланцевой золы $\left(\mathrm{CaCl}_{2}, \mathrm{MgCl}_{2}, \mathrm{NH}_{4} \mathrm{Cl}\right)$, способствует значительному уменьшению не только величины, но и продолжительности объемных изменений (фиг. 6 , кривые 5-7). Это пронсходит в связи с тем, что в присутствии этих добавок уже в первый час твердения значительно ускоряєтся гидратация извести, ангидрита и связывание их гидратов в новообразования. В результате этого уже в первые минуты звердения прочность вяжущего достигает значительной величины, спо- 
собноӥ противостоять возникающим напряжениям, благодаря чему спада прочности не наблюдается. Например, при введении в золу 1,0\% $\mathrm{NH}_{4} \mathrm{Cl}$ объемные изменения практически заканчиваются к 3,5 часам, достигая увеличения на $28,5 \%$ от первоначального объема; при увеличении добавки $\mathrm{NH}_{4} \mathrm{Cl}$ до $5 \%$ максимальное увеличение объема составляет только $14 \%$ и заканчивается к двум часам (фиг. 6 , кривые 4,7 ). Точно такое же явление значительное уменьшение объемных изменений, наблюдается и в вяжущем, твердеющем с 3,0 и $5,0 \%$ хлористого кальция. В присутствии $3,0 \% \quad \mathrm{CaC}_{2}$ гидратационное твердение прнсутствующей в золе $\mathrm{CaO}$ к двум часам твер-

Фиг. 7. Влияние величины объемных изменений вяжущего, твердеющего при $80^{\circ} \mathrm{C}$ в прнсутствин $3,0 \% \quad \mathrm{CaCl}_{2}$, на пластическую прочность. Heraшеная молотая пылевидная зола: 1 - общая степень гндратации $\mathrm{CaO}:$ \& $-\mathrm{CaO}$, связанная в новообразования; 3 пластнческая прочность; 4 объемные изменения, \% от

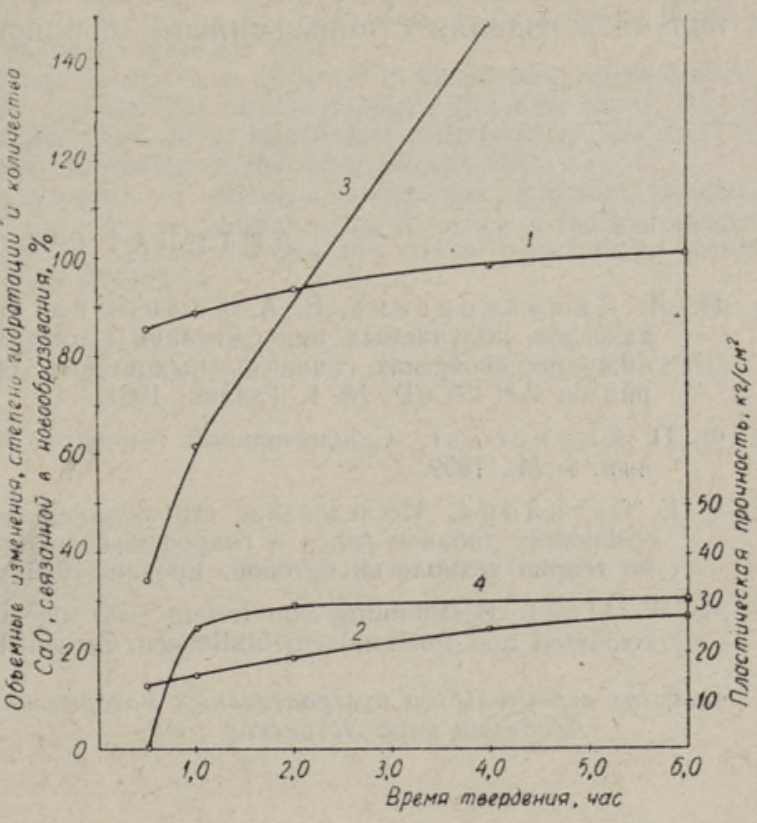
максимальных.

дения ускоряется в 1,5 раза, объемные изменения уменьшаются почти в 2,5 раза, а пластическая прочность возрастает в шесть раз и в дальнейшем ее падения не отмечается (ср. фиг. 5 и 7 ).

Таким образом, введение хлоридов в сланцезольное вяжущее, твердеюшее при $80^{\circ}$, позволяет практически нолностью использовать эффект гидратационного твердения присутствующих в золе извести и ангидрита. Поэтому эти добавки, как улучшающие структурно-механические свойства твердеющего при $80^{\circ}$ вяжущего, целесообразно применять при изготовлении ячеистых бетонов, подвергаемых пропариванию до автоклавной обработки. Это даст возможность не только сократить время предварительного пропаривания, но и получать изделия с лучшими прочностными свойствами.

\section{Выводы}

1. Гидратащионное твердение извести, ангидрита и образование гид. росульфоалюмината кальция представляют собой основные факторы, өпределяющие формирование первичного скелетного сростка при твер дении негашеной пылевидной сланцевой золы.

2. Частичное разрушение первичного сростка в твердеющем при $80^{\circ}$ вяжушем является следствнем появления значительных объемных из. 
менений при продолжающемся процессе гидратации извести и ангидрнта, что позволяет говорить о недостаточно полном использовании эффекта гидратационного твердения при данном способе обработки негашеной сланцевой золы.

3. Введение небольших количеств химических добавок $\left(\mathrm{CaCl}_{2}\right.$, $\mathrm{NH}_{4} \mathrm{Cl}, \mathrm{MgCl}_{2}$ ) дает возможность, должным образом отрегулировав последовательность процессов гидратации и формирования первичного скелетного сростка, устранить вредное влияние объемных изменений и получать изделия с повышенными прочностными свойствами.

Л И Т Е Р А Т Р А

1. Н. Л. Дилакторский, Е. А. Гали бина, М. А, Кийлер, О фазовом составе зол, получаемых при сжигании кукерсита в пылевндном состоянии, и 0 вяжущих свойствах сланцезольных стекол, Тр. Ин-та стр-ва и строит. материалов АН ЭССР, № 1, Таллин, 1961.

2. Ф. П. Кив и сельг, Сланцезольный пенобетон в Эстонской ССР, Тр. НИИЖБ, вып. 8, М., 1959.

3. Е. Е. Сегалов а, Исследование структурообразования в цементных суспензиях и влияния добавок гипса и гидрофильного пластификатора (ССБ), Тр. совеш. по теории технологин бетонов, Ереван, 1956.

4. M. Wa $11 \mathrm{raf}$, Bestimmung von freiem $\mathrm{CaO}$ neben freiem $\mathrm{Ca}(\mathrm{OH})_{2}$ in Portlandzementen und Portlandzementklinkern, Zement-Kalk-Gips, H. 5, 1958.

\author{
Институт строительства и строительных материалов Поступила в редакщию \\ Академии наук Эстонской ССР \\ 14. III 1961
}

\title{
LUBJA JA ANHUDRIIDI HUDRATISEERUMISE KIIRUSE MÕJU PŌLEVKIVITUHK- SIDEAINE MAHUMUUTUSTELE JA PLASTILISELE TUGEVUSELE KIVINEMISE KORRAL
}

\author{
E. Galibina, \\ tehniliste teaduste kandidaat \\ N. Dilaktorski, \\ geoloogia-mineraloogia doktor
}

\section{Resümee}

Pōhiliseks faktoriks, mis otseselt määrab kasutamata pōlevkivituhk-sideaine esialgse struktuuri tekkimise kivinemisel, on lubja ja anhüdriidi kivinemine hüdratatsioonil ning kaltsiumhüdrosulfoaluminaadi moodustumine.

Sideaine kivinemisel $80^{\circ} \mathrm{C}$ temperatuuris tema struktuur osaliselt laguneb, mis on tingitud suurtest (kuni 50\%-listest) mahumuutustest. Seetōttu ei kasutata siis küllalt täielikult lubja kivinemist hüdratatsioonil.

Vähese hulga kaltsium-, magneesium- ja ammooniumkloriidi lisandamine sideainele vōimaldab reguleerida hüdratatsiooni ja esialgse struktuuri tekkimise järjekorda, seega -kõrvaldada mahumuutuste kahjulik toime ning saada suurema plastilise tugevusega tooteid. 


\title{
EFFECT OF THE VELOCITY OF HYDRATION OF LIME AND ANHYDRITE ON VOLUME CHANGES AND PLASTIC DURABILITY OF OIL-SHALE ASH STONE
}

\author{
E. Galibina, N. Dilaktorski
}

\section{Summary}

The hydrational hardening of lime and anhydrite and the formation of calcium hydro. sulphoaluminate are the main factors determining the formation of the primary skeleton coalescence at the hardening of unslaked oil-shale ash dust.

A partial destruction of the primary coalescence, observed in the binding agent hardening at $80^{\circ} \mathrm{C}$, is one of the results of considerable volume changes attaining about $50^{\circ} \%$ of the initial volume, which allows us to speak of an insufficient utilization of the effect of hydrational hardening at the present processing of the oil-shale ash dust.

An addition of inconsiderable amounts of chemical substances (calcium chloride, magnesium and ammonium) allows for a due regulation of the sequence of the hydrational processes, eliminates the adverse effect of volume changes and makes it possible to obtain products possessing heightened binding properties.

Academy of Sciences of the Estonian S.S.R.,

Institute of Building and Building Materials
Received

March 14th, I96I 